\title{
Activity-Based Teaching and Learning Approach and Students' Academic Performance: Evidence from Among Stakeholders from Barekese District Ashanti Region of Ghana
}

\section{Theophilus Apenuvor \\ Department of Science Education, Jasikan College of Education, Jasikan, Ghana}

Frank Yao Gbadago (Corresponding Author)

Department of Accounting Studies Education, Akenten Appiah-Menkah University of Skills Training \& Entrepreneurial Development, KUmasi, Ghana

Email: frankggh@yahoo.com

\section{Kwadwo Ankomah}

Ghana Communication Technology University, Takoradi

\section{Agnes Fafa Anthony}

Finance \& Accounts Department, Agricare Ltd, Kumasi, Ghana
Article History

Received: 16 July, 2021

Revised: 23 August, 2021

Accepted: 14 September, 2021

Published: 18 September, 2021

Copyright (C) 2021 ARPG \& Author

This work is licensed under the

Creative Commons Attribution International

(c) (i)

CC BY: Creative

Commons Attribution License 4.0

\begin{abstract}
In this study, the authors explored the level of awareness and views on the activity-based approach to teaching and learning (ABTLA) in enhancing skills, competency and academic performance among students and other stakeholders from Senior High Schools (SHS) and Colleges of Education (COE) in Barekese District of Ashanti Region of Ghana. A survey involving 510 various stakeholders was conducted within the Barekese District of Ashanti Region of Ghana, using sets of a self-administered structured questionnaire. The study revealed that the Ghanaian stakeholders of second cycle and COEs are highly aware of ABTLA and its potency for enhancing skills, competency and academic performance among students. Policy implications and further future research directions were provided.

Keywords: Activity-based teaching and learning; Education; Skills and competency acquisition; Academic performance; Barekese District of Ashanti Region of Ghana.
\end{abstract}

\section{Introduction}

Students' experience with their subject tutors may largely affect their desire and/or interest in pursuing the subject as a course of study or career in the subject area. This may also affect their academic performance in the subject of study. There could be varying means by which students may experience their subject tutors, namely, during class contact hours, carefully having close personal observation of the tutor's personal life experiences among others. These may have the great potency of influencing the students' interest and academic performance in the subject is the direct experience gained by students during class contact hours. The contact hours do not only accord the students the opportunity to observe but also to interact with the tutor to confirm or otherwise dispel opinions and views formed via other means. Similarly, it could be conjectured that student-tutor contact hours provide the best opportunity for the tutor to greatly impact his/er students positively. Thus, a subject tutor could possibly use these contact hours to make a significant bearing on the students by using good teaching methods including disposition, heightening the likelihood of impacting the students' academic performance.

Considering the importance of teaching and teaching methods as critical pedagogical tools in impacting knowledge and hence students' academic performance, it has attracted various researchers and scholars' attention and, accordingly, has been greatly researched leading to the emergence of several teaching and learning methods. Critical among these is the activity-based teaching and learning method as it helps the teaching and learning facilitator to engage students more in the process (Harfield et al., 2007; Khan et al., 2012). As posited by Means (1994), this approach to teaching and learning is student-centered and it is able to provide students with opportunities to take a more active role in their learning by shifting the responsibilities of organizing, analyzing, and synthesizing content from the teacher to the learner. As scholars such as Alexander and November (2010) have continued to argue for the need for tutors to engage students more during contact sessions, this necessitated the calls for the use of activity-based teaching and learning approach among various subject areas, including business management studies.

According to Commey et al. (2014), management is considered a critical aspect of every human endeavor as its principles permeate through other activities we undertake and/or stages of our life. As such, most second cycle schools (including teacher trainings) are required to study management, especially the principles thereof. However, the teaching and learning approaches adopted by many tutors is not inductive to learning, with students finding the subject boring and unsatisfying. Opinions and views in extant literature are: that tutors most often repeat subject matter that is already in textbooks; they don't make use of excellent contemporary case studies and examples to clarify the content; and tutors do all the talking without engaging their students nor soliciting for their participation. 
These, according to Hall (2006), results in many business management students being utterly negative about subjects in this area of study.

Consequently, this leads to poor class attendance, truancy and unavoidably poor academic performance in the subject and related issues. In most instances, the views are that, the few students that have the edge to attend classes, do so either for the fear that there may be possible formative assessment (such as tests, receiving examination guidelines or copying tests) during their absence. As such, they are forced to attend reluctantly.

Being engaged means that students are actively involved in the learning process during classroom hours and take responsibility for their own learning; and not just using only questions-and-answers teaching methods and group work assignment (Killen, 2007). This is said to be critical in facilitating students' understanding of the subject matter, develop problem solving skills and hence their academic performance (Boud and Feletti, 1991; Khan et al., 2012; Ranganath, 2013). If this is the case, then why hasn't there been much encouragement in activate students' engagement. Alternatively stated, why are teaching and learning facilitators reluctant to employ the activity-based approach despite its sterling advantages as suggested in literature (Hall, 2006; Killen, 2007) so as to facilitate the teaching and learning that leads to students' higher academic performance?

According to Commey et al. (2014), encouraging learning, and provision of supportive environment for learning helps to equip individuals with adequate business management skills and knowledge in all the functions of management. These functions include planning, organizing, directing, controlling, delegation, co-ordination, motivating staffing etc., which are in one way or the other activity involving. Although there is enough empirical evidence, which according to Khan et al. (2012), suggests that activity based methods of teaching promotes the development of higher-order skills and competency, such as critical thinking and problem solving, these methods have not been extensively used in teaching students, particularly in developing countries like Ghana where skills and competencies are most needed for development.

Further, the few empirical studies available on the activity-based method of teaching have only explored the importance of using activity-based approach to teaching students without examining their design and implementation as well as how these lead to improving students' learning outcomes and subsequently academic performance.

In Ghana, due to the implementation of the free Senior High School (SHS) programme, coupled with the vociferous discussions on falling educational standards and students' academic performance, this has resurrected the discussions on students' engagement in the course of direct contact hours so as to ensure maximum expected learning outcomes. This is important due to the need for development of quality manpower with appropriate competency and skills for economic development. There is an urgency to revisit this call and, more importantly, approaches to teaching and learning within our colleges of education and second cycle education within Ghana in particular and across the globe. This is the over-riding motivation for this current study.

Thus, on the basis of the foregoing, coupled with calls from scholars and researchers (see Khan et al. (2012)), this current study sought to explore the level of awareness and views as to whether the activity-based approach to teaching and learning could help in enhancing students' learning outcomes and, hence, academic performance using students from the second cycle educational institutions specifically the SHS and colleges of education from the Barekese District of Ashanti Region of Ghana together with some parents, tutors and administrators. Further, the study examines the factors that influences the views (if any) of the stakeholders on the activity-based approach to teaching and learning within the Ghanaian context.

The remainder of this paper is organized in the following manner: the next section presents a brief review of relevant related literature; thereafter, the research method employed is outlined. Following this, the results of our study are presented and discussed. Finally, important theoretical and practical implications emanating from the findings of this study are raised, along with limitations and suggestions for future research.

\section{Brief Review of Relevant Related Literature}

Activity-based teaching and learning is a method in which students learn to decide what they need to know so as to find success within the class and educational institutions and/or career (Glasgow, 1997). Activity-based learning has been promoted as an alternative to more traditional, teacher-centered instruction. Dewey (1938), advocated the need for providing activities in school, which should give students opportunities to test theories and explore issues more critically. This is expected to help the learners to appreciate what they learn in the classroom. Further, it is anticipated that this will promote high-quality learning outcomes as students assume greater control over their own learning (Boud and Feletti, 1991).

Learning, as put forward by Vygotsky (1978), is a social process in which learners develop understanding through interaction with the environment around them. The most effective learning environment will be the one where students are provided with the opportunity and/or ability to explore concepts that were of interest to them, and discuss and negotiate the meaning of those concepts with other students as well as the facilitator.

According to extant literature in the teaching and learning domain, there is the need to advocate for more student-centered learning activities (Duffy and Jonassen, 1992). Thus, recognizing the need to provide students with necessary resources to help solve problem is the most important consideration in designing an instructional activity, as was suggested by, Jonassen (1991) and Bednar et al. (1992).

Accordingly, Balapumi and Aitken (2012)explains that, where instructors create such classroom opportunities for learners, it helps to enhance self-regulatory learning that assists in the development of independency for life-long learning. In this case, the tutor ceases to be master (that is personification of knowledge) but rather assumes the role of a facilitator or a knowledgeable organizer of student groups. Thus, if properly applied, the activity-based approach 
could help not only in improving students' academic performance but also arouse and stimulate students' interest in the subject.

\section{Research Methodology}

This study is a quantitative study using a survey design where a structured questionnaire was used as a data collection instrument as it was deemed to be one of the most appropriate methods in collecting high quality primary data (Said and Khasharmeh, 2014) within shortest possible time (Gbadago, 2015).

Upon completion of the review of relevant related literature, the data collection instrument (questionnaire) was developed, forming part of a larger study. The section of the instrument adopted for the data analysis for this current study consists of five (5) items categorized into two main subsections, namely: demographic profile of the study participants; and the section on the research objective.

The sample consists of various stakeholders of education consisting of school administrators, tutors, parents, students and employees who work in public taxation agencies. Overall, about 650 sets of the questionnaire were given out to the above mentioned stakeholders on activity-based teaching and learning and expected outcome in terms of improvement in students' understanding, academic performance and acquisition of skills and competency. Out of the 650 sets administered, about 510 completed instruments were returned, representing a response rate of 78.5 per cent.

The data collected was coded and input into SPSS Version 22 to enable analysis. The statistical analytical technique used to aid discussions and conclusion for this study was frequency distribution tables.

\section{Results and Discussions}

The results of this study are presented in two sections, namely: the demographic profile of the study participants; and analysis of the results.

\subsection{Demographic Profile of the Study Participants}

The study revealed that the studied respondents were made up of $80 \%$ males and $20 \%$ females suggesting the male stakeholders dominance in the sample used as shown in Table 1. The study respondents' ages ranged between 14 years and 60 years. From Table 1, it could be realized that those in age grouping 14-20 years dominated as this constituted about $32.94 \%$ of the respondents' age cohort. This is followed by those with age grouping 31-35 years constituting about $14 \%$ of the studied stakeholders' age cohort.

Table-1. Background Information on Study Participants

\begin{tabular}{l|l|l|l}
\hline Variable & Measurement & Frequency & Percentage (\%) \\
\hline & Male & 408 & 80.00 \\
\hline Gender & Female & 102 & 20.00 \\
\hline & $14-20$ & 168 & 32.94 \\
\hline & $21-25$ & 39 & 7.65 \\
\hline & $26-30$ & 36 & 7.06 \\
\hline Age & $31-35$ & 71 & 13.92 \\
\hline & $36-40$ & 59 & 11.57 \\
\hline & $41-45$ & 65 & 12.75 \\
\hline & $46-50$ & 37 & 7.25 \\
\hline \hline & $51-55$ & 25 & 4.90 \\
\hline Occupation & $56-60$ & 10 & 1.96 \\
\hline & Student & 214 & 41.96 \\
\hline & Administrator & 105 & 20.59 \\
\hline \hline & Tutor & 95 & 18.63 \\
\hline & Industry & 71 & 13.92 \\
\hline Educational Background & Others & 25 & 4.90 \\
\hline & Still in College & 214 & 41.96 \\
\hline & Diploma & 78 & 15.29 \\
\hline & Teacher Training Certificate & 79 & 15.49 \\
\hline & Degree & 112 & 21.96 \\
\hline & Non-formal Education & 27 & 5.30 \\
\hline & TOTAL & $\mathbf{5 1 0}$ & $\mathbf{1 0 0 . 0 0}$ \\
\hline
\end{tabular}

Source: Authors' Field Survey, October-December, 2018

Considering the focus of the current study, there is the need to examine the occupation background of the respondents as this has a bearing on the applicability of the respondents' previous educational endeavors. The results of the study revealed that the current participants who are currently in school constituted about $41.96 \%$, and those in the administration of various organizations constituted $20.59 \%$. Similarly, those who are tutors are made up of $18.63 \%$ while $13.92 \%$ and $4.90 \%$ are in industry and other endeavors as shown in Table 1. 
Education is considered highly in this current study as it has an impact on the problem under study; that is, prior educational endeavors coupled with experience as well as requisite application of what have been learnt in the past may greatly influence one's knowledge and appreciation of the current research problem. Consequently, this study considered the educational background of the respondents and found that they were highly educated as about 53\% are educated with various certificates (such as Diploma (15.29\%), Teacher Training Certificates (15.49\%), degree $(21.96 \%), 41.96 \%$ were still in school while only $5.30 \%$ do not possessed any formal educational certificates as shown in Table 1. This suggests that the respondents possessed the right disposition to appropriately participate in the current study.

\subsection{Analysis of the Results}

From the results as reported in Table 2, the study further ascertained that $74.12 \%$ of the respondents are aware of the activity-based teaching and learning approach (ABTLA) and its application while $25.88 \%$ are not.

Table-2. Whether Participants are Aware of ABTLA as a Pedagogical Technique

\begin{tabular}{l|l|l}
\hline Are you Awareness of ABTLA? & Frequency & Percentage (\%) \\
\hline Yes & $\mathbf{3 7 8}$ & $\mathbf{7 4 . 1 2}$ \\
\hline No & $\mathbf{1 3 2}$ & $\mathbf{2 5 . 8 8}$ \\
\hline TOTAL & $\mathbf{5 1 0}$ & $\mathbf{1 0 0 . 0 0}$ \\
\hline Source: Authors' Field Survey, October-December, 2018
\end{tabular}

This suggests that the majority of the stakeholders studied can profess their knowledge and awareness of this pedagogical approach; thus, indicating a high level of awareness among the key stakeholders.

Table-3. ABTLA Usage as an Effective Pedagogical Technique for Positive Teaching \& Learning Outcomes

\begin{tabular}{l|l|l}
\hline $\begin{array}{l}\text { Participants' Awareness and/or Belief that ABTLA Usage } \\
\text { May Lead to Positive Teaching \& Learning Outcomes? }\end{array}$ & Frequency & Percentage (\%) \\
\hline Strongly Agree & 204 & 40.00 \\
\hline Agree & 161 & 31.57 \\
\hline Neutral & 13 & 2.55 \\
\hline Not Agree & 120 & 23.53 \\
\hline Strongly Not Agree & 12 & 2.35 \\
\hline TOTAL & $\mathbf{5 1 0}$ & $\mathbf{1 0 0 . 0 0}$ \\
\hline
\end{tabular}

To probe further on the research objective as to whether participants support the view that ABTLA usage as a pedagogical technique could lead to positive expected teaching and learning outcomes, $71.57 \%$ of the respondents indicated an agreement, while about $25.88 \%$ and $2.55 \%$ seem not to agree or remained indifference respectively as shown in Table 3.

Table-4. Participants' Views on Tutors' ABTLA Usage Students' Teaching \& Learning Outcomes and Academic Performance

\begin{tabular}{l|l|l}
\hline $\begin{array}{l}\text { Tutors' Usage of ABTLA in Teaching \& Learning } \\
\text { Outcomes enhances Students' Academic Performance? }\end{array}$ & Frequency & Percentage (\%) \\
\hline Strongly Agree & 209 & 40.98 \\
\hline Agree & 117 & 22.94 \\
\hline Neutral & 52 & 10.20 \\
\hline Not Agree & 72 & 14.12 \\
\hline Strongly Not Agree & 60 & 11.76 \\
\hline TOTAL & $\mathbf{5 1 0}$ & $\mathbf{1 0 0 . 0 0}$ \\
\hline
\end{tabular}

Source: Authors' Field Survey, October-December, 2018

However, from Table 4, it is apparent that about $63 \%$ of the respondents indicated that ABTLA usage by teaching and learning tutors could help in enhancing academic performance and other related outcomes such as skills and competency acquisition among students from second cycle and teacher training institutions. That is, most participating stakeholders studied confirmed that ABTLA usage during tutor and students contact hours could lead to improvement in students' understanding of lessons and, more importantly, acquire relevant skill sets and competency as well as their academic performances as posited in literature.

Overall, the above findings confirmed the views in literature regarding the usage of ABTLA in enhancing teaching and learning outcomes including skill acquisition, competency and academic performance as observed by researchers and scholars such as Jonassen (1991), Duffy and Jonassen (1992), Bednar et al. (1992), Means (1994), , Alexander and November (2010), Ranganath (2013) among others. 


\section{Conclusions and Implication}

This study could not be said to be without limitations, especially considering the coverage and the level and/or rigor of statistical analysis employed. However, as exploratory study, it may be highly appreciated for its lead role in the call for re-examining the role ABTLA could play in skills, competency and academic performance among Ghanaian students at this critical stage of our development where skills and competency is considered a critical requirement for job placement in general and the Ghanaian setting in particular. It is moreover noted for being one of the few studies that lead the way in understanding how ABTLA could improve student tutor effectiveness during class contact hours.

This study sought to ascertain stakeholders' level of awareness and views on the activity-based approach to teaching and learning (ABTLA) in enhancing skills, competency and academic performance among students from Senior High Schools (SHS) and Colleges of Education (COE) in Ashanti Region of Ghana. The study concludes that there is a high level of awareness of ABTLA usage and/or application in enhancing skills, competency and academic performance among Ghanaian students. The findings from this study appear to suggest that the majority of the studied stakeholders embraced the usage and/or adoption of ABTLA in lesson delivery. Considering ABTLA potency in enhancing students' skills and competency acquisition as well as improve their academic performance, its immediate adoption by all tutors is highly recommended. On this basis, it is being suggested to policy maker and administrators of educational institutions in Ghana that they should step in with the right policies in this direction. Considering the limitation of this study, the findings might therefore not reflect the entirety of the situation in Ghana as such, further studies that examines the determinants of ABTLA as well as samples from other regions of the country are highly recommended.

\section{References}

Alexander, G. and November, I. (2010). Objectives in South African higher education: Imagine that! Journal of Science, 24(2): 101-09.

Balapumi, R. and Aitken, A. (2012). Concepts and Factors Influencing Independent Learning in IS Higher Education. Independent Learning in IS Higher Education. 1-10.

Bednar, A., Cunningham, D., Duffy and Perry, J. (1992). Theory into Practice: How Do We link? Int.

Boud, D. and Feletti, G. (1991). The challenge of problem-based learning. St. Martin"es Press: New York.

Commey, V., Howard, E. K. and Turkson, J. K. (2014). Assessment of sustainable competitive advantage of selected hotels in Kumasi using the generic functions of human resource management model. The International Journal of Business \& Management, 2(11): 34-44.

Dewey, J. (1938). Experience and education. Macmillan: New York.

Duffy, T. M. and Jonassen, D. H. (1992). Constructivism and the technology of instruction: A conversation. Lawrence Erlbaum Assoc. Inc.: New Jersey.

Gbadago, F. Y. (2015). Audit expectation gap and mba accounting students' knowledge on auditor(s)'s responsibilities: Evidence from a public university in kumasi ashanti region of ghana. J. Account. Tax, 7(4): 53-61.

Glasgow, N. (1997). New curriculum for new times: A guide to student-centered, problem-based learning. Corwin: Thousand Oaks, CA.

Hall, A. R. (2006). Families, Children and Communities in a Multicultural and Diverse Society. 1021-35. Available: http://eric.ed.gov/.1021-1035

Harfield, T., Davies, K., Hede, J., Panko, M. and Kenley, R. (2007). Activity-based teaching for unitec new zealand construction students. Emirates Journal for Engineering Research, 12(1): 57-63.

Jonassen, D. (1991). Evaluating constructivist learning. Educational Technology Publications Inc., 31(9): 28-33.

Khan, M., Muhammad, N., Ahmed, M., Saeed, F. and Khan, S. A. (2012). Impact of activity-based teaching on students' academic achievements in physics at secondary level. Academic Research International, 3(1): 146-56.

Killen, R. (2007). Effective teaching strategies. 4th ed. edn: Thomson Learning Nelson: Scarborough, Canada.

Means, B. (1994). Introduction: Using technology to advance educational goals. In b. Means (ed.), technology and education reform: The reality behind the promise. Jossey-Bass: San Francisco.

Ranganath, N. S. (2013). Activity based learning: An effective model for business schools. The Journal of Commerce, 4(1): 17-23.

Said, K. and Khasharmeh, H. (2014). Auditors' perceptions on impact of mandatory audit firm rotation on auditor independence -Evidence from Bahrain. Journal of Accounting and Taxation, 6(1): 1-18.

Vygotsky, L. S. (1978). Mind in society: The development of higher psychological processes. Harvard University Press: Cambridge, Mass. 